+ 900 ASYMPTOMATIC hYPOGaMMAgLOBULINEMia IN A MOTHER PRESENTING AS NEONATAL MENINGITIS IN TWO SIBLINGS. Gregory S. Milleville, John H. Kersey and Rolf R. Engel, Hennepin County Medical Center and University of Minnesota, Dept. of Pediatrics, Minneapolis.

The unusual occurrence of group B streptococcal (GBS) disease in siblings lead to immune studies of a boy who mimicked his older sister in developing septicemia and meningitis from GBS by the 4 th day of life.
His serum IgG level was only $40 \mathrm{mg} \%$. His IgM was 36 and IgA was $<7$. Maternal levels were all low: IgG 40, IgM 36, IgA 14 and IgE $<10 \mathrm{mg} \%$.

Despite 14 days of penicillin and intravenous immunoglobulins, the boy's GBS (type Ic) meningitis recurred within 3 days with fever and a rise in the CSF leukocyte count from 20 to 2,025 . He recovered completely during 2 more weeks of antibiotic $T x$ and at 7 months his Ig levels are normal. His sister had neonatal septicemia, meningitis, septic arthritis, and pneumonia which responded to 32 days of $\mathrm{Tx}$. At 3 years, she is healthy with normal Ig levels: IgG 761, IgM 113 , and IgA $62 \mathrm{mg} \%$.

The mother is healthy and has not had excess infections. GBS (type Ic) was also recovered from her vagina. She was unresponsive to rubella immunization. She has low levels of IgA in saliva: $2 \mathrm{mg} \%$, and breast milk: $3 \mathrm{mg} \%$. Her panhypogammaglobulinemia is associated with normal numbers of $B$ cells that have IgA, IgG, and IgM surface markers. Her lymphocytes had a normal in vitro response to phytohemagglutinin, Concanavalin $A$, and pokeweed mitogen.

This unique family emphasizes the importance of passive immunity in protecting newborns against GBS and it suggests that serious bacterial infections in neonates should prompt inquiry into the mother's immune competence.
093 BONE MARROW (BM) LYMPHOID PROGENITOR CELLS IN SEVERE COMB INED IMMUNODEF ICIENCY (SCID). Steven Neudorf, John Kersey, Alexandra Filipovich, University of Minnesota, Minneapolis, Minnesota.

SCID is a heterogeneous disorder often associated with lymphopenia; hypothesized to be due to defective lymphoid differentiation or proliferation. We studied this hypothesis by analyzing BM mononuclear cells from $6 \mathrm{pt}$ with SCID (as well as 5 age matched controls) for the presence of lymphoid progenitor cells. Such cells are $\mathrm{E}$ rosette , surface $\mathrm{Ig}^{-}$and include cells that express terminal transferase (TDT), the cormon ALL antigen (CALLA) or p24. BM cells were studied using immunofluorescent microscopy. terns were seen. Group $1(n=2)$ with no detectable. Two patgenitor cells were more lymphopenic $(p=.03)$ than pt in group 2 $(n=4)$. Both groups were more Tymphopenic than age matched controls $(p=.04)$. All pt had SCID based on absent response to mitogens, recurrent infections and failure to thrive. $5 / 6 \mathrm{pt}$ had hypogammaglobulinemia. Group 2 contained $1 \mathrm{pt}$ with adenosine deaminase deficiency on transfusion therapy and $1 \mathrm{pt}$ with the spurious lymphocyte syndrome. These results suggest that some pts with SCID have reduced numbers of BM lymphoid precursors and the absence of such cells may be related to the severity of lymphopenia seen.

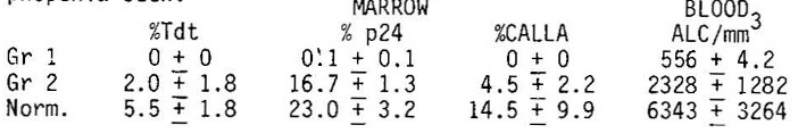

$23.0 \mp 3.2$

\section{SERUM AND MILK ANTIBODY LEVELS TO GIARDIA}

991 LAMBLIA Paolo Miotti, Robert Gilman, Larry

Pickering, Guillermo Ruez Palacios, Thomas Cleary, Robert Medical School, Houston, Institute of Nutrition, Mexico City.

There is little data relating to the prevalence and role of systemic and local antibody to Giardia lamblia (GL) antigens in mothers and children living in different environments. We obtained human milk and serum specimens from mothers and children living in Dacca, Bangladesh, Baltimore (MD) Houston (TX) and Mexico City. We compared the prevalence and levels of milk IgA and serum IgG antibodies to GL in the different populations by means of an ELISA assay utilizing purified antigens from cultured GL organisms. We found that 101/104 (97\%) mothers living in Bangladesh, 22/26 (84\%) mothers living in Maryland $9 / 17$ (52\%) mothers living in Texas and 23/37 (67\%) mothers living in Mexico had detectable levels of milk IgA antibody to GL. The levels (geometric mean $+/-\mathrm{SD}$ ) of antibody in the milk samples from mothers in (geometric mean $+/-\mathrm{SD})$ of antibody in the milk samples from mothers in
Bangladesh $(11.25+/-.16 \mathrm{\mu g} / \mathrm{ml})$ and Mexico $(17.69+/-1.22 \mathrm{\mu g} / \mathrm{ml})$ were significantly greater than the levels detected in the women living in Maryland $(1.78+/-1.11 \mu \mathrm{g} / \mathrm{ml})$ or Texas $(1.70+/-.097 \mu \mathrm{g} / \mathrm{ml})$. In terms of total milk IgA, the IgA directed at GL in Bangladesh (1.54\%) and Mexico $(3.20 \%)$ were significantly greater than the corresponding percentages in Maryland $(0.59 \%)$ and Texas $(0.70 \%)$. Analysis of serial specimens obtained from lactating mothers over a period of 2 years revealed that most of the mothers had a constant level of antibody, although occasional increases in milk and serum antibody levels were noted. These studies indicate that serum and milk antibodies to GL are widely prevalent throughout the world but that the levels of milk antibody are significantly higher in areas of high exposure to $\mathrm{GL}$.

NATURAL KILLER (NK) LYMPHOCYTE ACTIVITY ENHANCED BY INTERFERON. Ayman E1 Mohandes and D. Spencer Brudno
(sponsored by Glen Rosenquist) George Washington (sponsored by Glen Rosenquist) George Washington
School of Medicine, Department of Child Health and University School of Medicine, Department of Child Hea
Development, Division of Neonatology, Washington, D.C.

NK activity was studied in cord blood 1ymphocytes using K562 target cells. The mononuclear layer was depleted using an adherence technique. High effector to target ratios $(50: 1$ and $100: 1$ ) were used in an 18 hour Chromium(51) release assay. K562 lysis was then measured after cord blood lymphocytes were lysis was then measured after cord blood lymphocytes
incubated with interferon ( $1000 \mathrm{U} / \mathrm{ML}$ and $2000 \mathrm{U} / \mathrm{ML})$.
EFFECTOR: TARGET BASELINE

INTERFERON (2000 U/ML)
INTERFERON $(1000 \mathrm{U} / \mathrm{ML})$
$50: 1$ Adu1t $(\mathrm{N}=7) \quad 13.4 \pm 2.3 \times 4$ Infant $(\mathrm{N}=10) \quad 3.1 \mp 0.7$ $\begin{array}{lr}\text { Adult }(\mathrm{N}=7) & 19.8 \mp 3.3 * \\ \text { Infant }(\mathrm{N}=10) & 7.8 \mp 2.3\end{array}$ Adult $(\mathrm{N}=6) \quad 21.8 \mp 2.3 *$ Infant $(\mathrm{N}=9) \quad 9.7 \mp 7.1$
$100: 1$ $21.9 \pm 2.5 * *$ $7.0 \pm 2.6$ $26.3 \pm 1.9 *$ $9.0 \pm 3.1$ $8.4 \pm 2.3 * *$ Means + S.E.M. * p<.005, ** p<.001 Adu1ts vs. Infants

NK activity was found to be statistically lower than adult means with both E:T ratios at baseline activity and after interferon' enhancement. However, at the $100: 1$ ratio cord blood lymphocytes enhanced with $2000 \mathrm{U} / \mathrm{ML}$ of interferon showed a decline in the enhancement curve which could represent the effect of higher concentrations of interferon on suppressor lymphocyte subpopulations in the neonate.
Norm. 